\title{
Guidance of Callosal Axons by Radial Glia in the Developing Cerebral Cortex
}

\author{
Carolyn R. Norris ${ }^{1, a}$ and Katherine Kalil ${ }^{1,2}$ \\ 'Neuroscience Training Program and 'Department of Anatomy, University of Wisconsin, Madison, Wisconsin 53706
}

During development, columns of the mammalian cerebral cortex are formed by migration of neurons along fascicles of radial glia. Subsequently, axons of the corpus callosum connect reciprocal regions of each cerebral hemisphere. To determine whether the radial growth of callosal afferents through the developing cortex may be guided by particular cellular elements, we examined the ultrastructural relationship between callosal afferents and radial fibers in the early postnatal hamster sensorimotor cortex. Developing callosal axons and their growth cones were labeled with HRP injected into the cortex at $3 \mathrm{~d}$ postnatal when the growth cones have extended across the callosum and are just entering the contralateral cortex. An EM analysis of $30 \mathrm{HRP}$-labeled axons and their growth cones revealed that they extended upon fascicles of radial processes associated with migrating neurons. Reconstruction of seven of these growth cones, serially sectioned in their entirety, showed that growth cones were associated with the same radial fascicle as their axon. Growth cones also touched other cellular elements such as axons. However, the finding that callosal afferents, from the point at which they enter the cortex to their growth cones, were apposed to a continuous fascicle of radial fibers suggests that callosal axons are tracking along radial processes. We conclude that the majority of the radial processes within fascicles are likely to be glial, based on their relatively large dlameters, electron-lucent cytoplasm with a regular array of microtubules, the presence of glycogen granules, occasional cytoplasmic protrusions lacking microtubules, and their consistent association with migrating neurons. We propose therefore that radial glia may serve a guidance function for growing callosal axons in their radial trajectory through the developing cerebral cortex.

The adult mammalian neocortex consists of topographically organized columns of functionally related neurons (Mountcastle, 1957; Hubel and Wiesel, 1962). Axons of the corpus callosum connect reciprocal regions of each cerebral hemisphere

\footnotetext{
Received Jan. 7, 1991; revised May 16, 1991; accepted June 11, 1991.

We acknowledge Art Lies for excellent technical assistance with the electron microscopy, especially the serial sectioning. We are grateful to Cheryl Adams for help with the artwork and photography. Mary Behan, Mary Halloran, Ronald Kalil, and Michael Merline read earlier versions of the manuscript and provided helpful comments. We are also indebted to Ronald Kalil for providing the JAvA morphometric analysis. This work was supported by NIH Grant NS14429 (to K.K.) and Training Grant T32 GMO07507.

Correspondence should be addressed to Katherine Kalil, Department of Anatomy, University of Wisconsin, 1300 University Avenue, Madison, WI 53706.

a Present address: 3400 North Charles Street, Department of Biology, Mudd Hall, The Johns Hopkins University, Baltimore, MD 21218.

Copyright (C) 1991 Society for Neuroscience $0270-6474 / 91 / 113481-12 \$ 05.00 / 0$
}

(Jones et al., 1975, 1979; Yorke and Caviness, 1975; Wise and Jones, 1976; Akers and Killackey, 1978; Killackey et al., 1983; Miller and Vogt, 1984; Olavarria et al., 1984; Carvell and Simons, 1987; Koralek et al., 1990). During development, cortical columns are formed by migration of neurons along fascicles of radial glia (Rakic, 1988). The pioneering work of Rakic (1971b, 1972) showed an intimate relationship between newly generated neurons and radial glia as neurons migrate from their zone of generation to their final destination in the cerebral cortex. A central unanswered question is how growing callosal axons extend through the developing cerebral cortex to find their appropriate targets. One possibility is that the growth cones of callosal afferents also use radial glial fascicles to guide their extension through the developing cortex.

Increasing evidence supports the hypothesis that radial glia differentiate into astrocytes (Choi and Lapham, 1978; Schmechel and Rakic, 1979; Levitt and Rakic, 1980; Hirano and Goldman, 1988; LeVine and Goldman, 1988; Engel and Muller, 1989; Voigt, 1989; Culican et al., 1990), suggesting that like astrocytes, their surface may also provide a permissive substrate for axon outgrowth (Noble et al., 1984; Fallon, 1985). In addition, radial glia are positioned appropriately to guide axonal growth in the cerebellum (Rakic, 1971a); neocortex (Rakic, 1972); spinal cord, medulla, and pons (Dupouey et al., 1985; Bitner et al., 1987); optic pathway (Guillery and Walsh, 1987; Wilson et al., 1988); and LGN (Sretevan and Shatz, 1987). It has therefore been suggested that radial glia may be important for axonal guidance in the vertebrate CNS. However, close apposition of growing axons and radial glia has never been demonstrated directly to support this hypothesis.

In several neural systems, the orientation and position of glia and other non-neuronal cells early in development has led to the suggestion that they may provide a preformed pathway for the guidance of growing axons. For example, evidence that glia provide a permissive substrate for axonal outgrowth in vivo has come from studies in the mouse corpus callosum. Disruption of the astroglial "sling" at the cerebral midline prevents growth of callosal axons across the midline (Silver et al., 1982), and insertion of a nitrocellulose bridge allows blockaded callosal axons to regrow if the insert becomes coated with astroglia (Smith et al., 1986). In addition, recent studies in invertebrates have demonstrated that glial cells may not only provide a scaffold essential for axon outgrowth but may guide specific subsets of commissurally projecting axons (Jacobs and Goodman, 1989).

The developing rodent corpus callosal pathway is an excellent system in which to investigate the role of glia in CNS axon guidance because of its homotopic pattern of connections (Jones et al., 1975, 1979; Yorke and Caviness, 1975; Wise and Jones, 


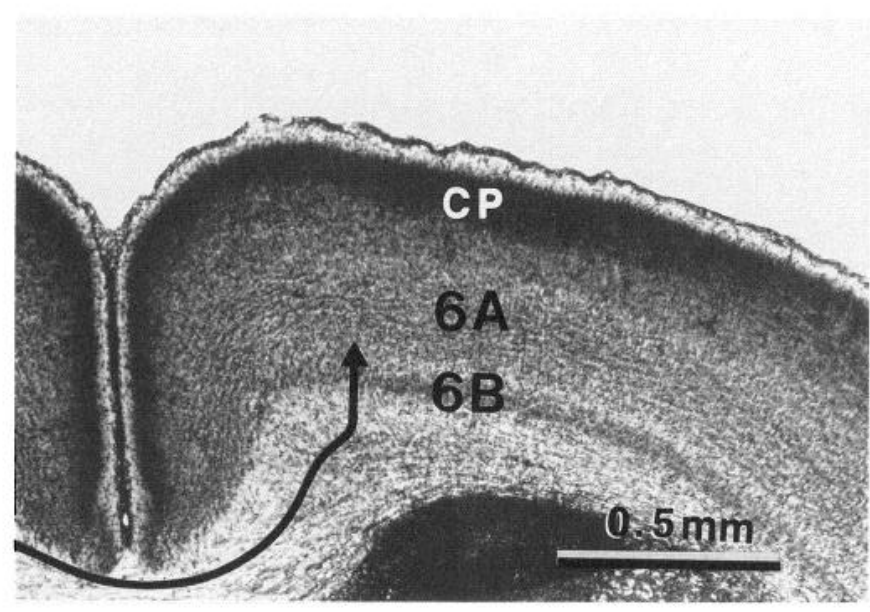

Figure 1. Nissl-stained section through the sensorimotor cortex of a hamster $3 \mathrm{~d}$ postnatal, which is the approximate age investigated in the present study (2.5-3 d postnatal). Midline is to the left. At this age, all cortical neurons have been generated, but many are still migrating. Layers $6 A$ and $6 B$ have differentiated from the cell-dense cortical plate $(C P)$. A schematic representation (arrow) of an HRP-filled callosal afferent with its growth cone in lower layer $6 \mathrm{~A}$ (and its cell body in the opposite cortex) is drawn to illustrate the position of callosal afferents examined in the present study.

1976; Akers and Killackey, 1978; Killackey et al., 1983; Miller and Vogt, 1984; Olavarria et al., 1984; Carvell and Simons, 1987; Koralek et al., 1990). A further advantage is that, in the hamster, much of axon outgrowth in the callosum occurs postnatally (Silver et al., 1982; Norris and Kalil, 1990). In a previous study, we showed that callosal afferents first extend radially (perpendicular to the pial surface) through the cortex and, with rare exceptions, do not begin to extend lateral branches until the age that the cortical plate disappears and the first callosal axons reach the outer layer of the cortex (Norris and Kalil, 1989). Thus, until relatively late in their development, the trajectory of callosal afferents is parallel to the orientation of radial glial fibers. In the present study, we have used EM HRP techniques to investigate directly the ultrastructural relationship between callosal afferents and radial glia in the developing hamster neocortex. We found that callosal axons contact a continuous fascicle of radial fibers throughout their cortical trajectory, and we present supporting evidence that these radial fibers are glial. The results suggest an important role for radial glia in the guidance of callosal afferents.

\section{Materials and Methods}

Golden hamsters (Mesocricetus auratus) 2.5-3.5 d postnatal were used in these studies. Postnatal day $0(\mathrm{P} 0)$ was considered to be $15.75 \mathrm{~d}$ after mating, regardless of the actual time of birth.

The injection procedure and histological methods used in the present study are similar to those described previously (Norris and Kalil, 1990). Briefly, neonatal animals were anesthetized by cooling, and a small region of presumptive sensorimotor cortex was exposed by removing the skull and dura with a blunt $(25 \mu \mathrm{m})$ glass pipette tip. Gelfoam soaked in a $2-4 \%$ HRP solution was dried onto a $15 \mu \mathrm{m}$ pipette tip that was then inserted into the cortex to a depth of $0.5 \mathrm{~mm}$. Two to three hours after the injection of HRP, animals were transcardially perfused with $10 \mathrm{ml}$ of saline followed by $20-30 \mathrm{ml}$ of $0.6 \%$ paraformaldehyde, $3 \%$ glutaraldehyde, $0.01 \%$ tannic acid at a constant flow rate of $0.45 \mathrm{ml} /$ min by means of a Sage perfusion pump. Coronal sections $(80 \mu \mathrm{m})$ were cut on an Oxford vibratome and reacted for the histochemical localization of HRP with a nickle-cobalt intensification step (Adams, 1981). Sections containing HRP-labeled callosal afferents in the cortical hemi- sphere contralateral to the injection site were postfixed for 1-2 hours in $1 \% \mathrm{OsO}_{4}$, dehydrated in a series of alcohols, and embedded between two sheets of Aclar plastic. In later experiments, we postfixed the sections with $1 \% \mathrm{OsO}_{4}$ with $1.5 \%$ potassium ferrocyanide (reduced osmium) in order to preserve glycogen granules (Gadisseux and Evrard, 1985). Following dehydration, sections were again examined in the light microscope, and growth cones and their axons were drawn with the aid of a camera lucida and photographed. Sections containing isolated growth cones were cut out of the Aclar, mounted on blank Epon blocks, and serially sectioned at $2 \mu \mathrm{m}$ on an ultramicrotome. The semithin sections were dried onto glass slides and again examined uncoverslipped in the light microscope before they were remounted on blocks of resin and trimmed. The cortical portion of many callosal afferents was usually contained entirely within one or two semithin sections depending on whether the plane of section was parallel to the trajectory of the axon. Serial thin sections ( $70-90 \mathrm{~nm}$ ) were cut and collected onto Formvarcoated grids and stained with uranyl acetate and lead citrate.

Analysis of cellular contacts of HRP-labeled afferents. Thirty callosal axons and their growth cones were observed at the electron microscopic level. Each recovered thin section from all 30 callosal afferents was examined in the electron microscope to observe the cellular elements apposed to the HRP-labeled callosal axon. Of these 30 callosal afferents, 7 were successfully serial thin sectioned in their entirety. Reconstructions were made by serially aligning acetate overlays of photomicrographs of thin sections containing relatively large portions of the growth cone or axon (see Fig. 6). In this way, we obtained an image of the axon and its growth cone and the cellular elements in contact with the labeled processes. Five of the seven successfully serially sectioned afferents were randomly chosen to quantify the proportion of the axon and growth cone apposed to radial fibers and migrating neurons relative to other cellular elements. The cellular relationships of the two not included in the quantitative analysis did not appear qualitatively different from the other five axons and their growth cones.

\section{Results}

\section{Organization of developing sensorimotor cortex}

In a previous study, we showed that the first axons of the developing sensorimotor cortex begin to project across the callosum at birth, followed by successive waves of callosal axons and their growth cones. We found that no growth cones enter the contralateral cortex until 2 d postnatal (Norris and Kalil, 1990). At this age, neurons destined for all layers of neocortex have been generated, but migration of these neurons continues throughout the first postnatal week, so that the most superficial layers, which are the last to differentiate, cannot be distinguished until postnatal day 8 (Shimada and Langman, 1970). By 3 d postnatal, growth cones have extended dorsally into layer 6 , which is just differentiating from the cortical plate (Fig. 1). Thereafter, during the first postnatal week, callosal afferents continue to advance radially through the developing cortex but do not begin to extend branches until 7-8 d postnatal, concomitant with the disappearance of the cortical plate and the arrival of the first callosal afferents in the outer layer of cortex (Norris and Kalil, 1989).

In the present study, we focused on cortical development at 2.5-3 d postnatal when many callosal growth cones have begun to exit the callosum and have advanced into differentiating layer 6. At this age, the developing sensorimotor cortex is organized in a pattern of fascicles of fibers separated by neuropil and aligned perpendicular to the pial surface (see Fig. $2 C, D$ ). In the layers of cortex examined in this study, radial fascicles tended to remain separate from and parallel to adjacent radial fascicles, which were regularly spaced about 6-9 $\mu \mathrm{m}$ apart. However, this stereotyped organization of fascicles was not strictly maintained (see also Misson et al., 1988). Frequently, a bundle of fibers diverged from the fascicle to which it belonged to form an autonomous fascicle or to join an adjacent fascicle (see Fig. 4). Less frequently, an entire fascicle of fibers deviated up to $25^{\circ}$ 
from the radial axis until it reached a neighboring fascicle. Because of this divergence and convergence of processes, the composition of fascicles did not remain constant.

A column of migrating neurons readily identifiable by their bipolar shape and chromatin-dense nucleus asymmetrically placed in an electron-dense cytoplasm was associated with each fascicle of radially aligned fibers. Between the columns of $\mathrm{mi}-$ grating neurons were densely packed processes, running parallel to the pial surface (Fig. $2 C, D$ ). Based on their relatively small size and lack of ribosomes, these processes were assumed to be axons. Cell bodies of differentiating neurons, identified by a round nucleus with less dense chromatin, were also located between the radial columns in more superficial regions of the cortex (see Fig. 5).

\section{Relationship of callosal axons to radial elements of developing cortex}

Callosal growth cones and their axons were identified by HRP labcling, which resultcd in complete filling of axons and growth cones without damage artifacts. We examined 30 callosal afferents that had entered the contralateral cortex. Of these, seven growth cones along with the proximal portion of their axons were serially sectioned to investigate the relationship of callosal afferents to cellular elements of the developing cortex. Results of this analysis revealed that the entire cortical extent of the callosal axon was associated with a continuous group of radial fibers and its associated migrating neurons. This relationship is most clearly illustrated by the labeled callosal axon shown in Figure 2. Although the electron micrographs contained only intermittent segments of the HRP-labeled axon that weaved in and out of the section, it is clear that from the point at which the axon left the callosum to the base of its growth cone the axon retained its apposition with a single column of radial fibers. The association of callosal afferents with a discrete fascicle of radial fibers is also shown in Figures 3 and 4. The micrograph at higher magnification in Figure 3 reveals that the radially aligned fiber apposed to the HRP-filled process contained glycogen granules, which is consistent with the glial identity of the radial processes (see Discussion).

As mentioned above, the orientation of radial fascicles was not strictly radial. Fascicles frequently branched or converged. The callosal afferent shown in Figure 4 extended radially and tracked along a continuous bundle of fibers. However, when the radial fascicle branched, the callosal axon followed one of the developing branches, in this case the left one. Occasionally, two radial fascicles merged. In addition, in more superficial regions the organization of radial fibers into separate, parallel palisades was obscured by increasing numbers of immature neurons. Few callosal afferents were observed whose growth cones had penetrated into these superficial regions (Fig. 5). Reconstruction confirmed that the HRP-labeled callosal afferent remained associated with a continuous fascicle of radial fibers.

As shown in Table 1, the majority of the HRP-labeled callosal afferent membrane was apposed to radial fibers and their associated migrating neurons. For two reasons, these values actually tend to underestimate the amount of contact with largerdiameter radial fibers. First, some of the processes that we could not identify without ambiguity are likely to be radial processes weaving out of the plane of section and thus cut in cross section. Second, callosal axons often extend along the border between a radial fascicle and the axons cut in cross section. Along these portions of an axon, quantification would indicate that half of the axon was apposed to radial fibers and half was apposed to axons. In fact, in no instance did we observe HRP-labeled callosal axons in the neuropil isolated from a radially oriented fascicle. In addition, we observed that small unidentified processes were occasionally insinuated between the labeled axon and the larger radial fibers. These processes could be later-arriving, unlabeled callosal axons.

\section{Relationship of callosal growth cones to radial elements of developing cortex}

Of the 30 HRP-labeled growth cones examined ultrastructurally in relationship to their cellular environment, seven were serially sectioned in their entirety and reconstructed from thin sections. In all cases, growth cones were associated with radial fibers continuous with the fascicle associated with their axon. Portions of many growth cones also touched migrating neurons and other unlabeled axons and growth cones. Quantitative analysis presented in Table 1 reveals considerable variability in the proportion of the growth cone plasma membrane apposed to large electron-lucent radial fibers. One reconstructed growth cone with a tapered morphology shown in Figure 5 was insinuated between a fascicle of radial fibers and an immature neuron associated with the same fascicle, and no processes of this growth cone explored the neuropil surrounding its radial fascicle. In contrast, large growth cones extended processes into the neuropil surrounding their radial fascicle and thus touched more cellular elements. These associations are clearly illustrated in Figure $2 D$, which shows the contacts made by a branching growth cone. The middle and left branches of the HRP-labeled growth cone (see drawing in inset) extended along either side of a radial fiber that belonged to the same fascicle associated with its axon. The left branch of the growth cone, whose cellular relationships are best captured within a single thin section, touched a migrating neuron as well as its associated radial fibers. The right branch extended for a short distance into the regions between radial fascicles and touched several axons. However, in no instance, even for the largest growth cones, did growth cone processes extend beyond an adjacent radial fascicle. Even when a growth cone had advanced as far as a layer of neurons that were beginning to differentiate, its processes continued to associate with radial fibers continuous with those apposed to its axon. As shown in Figure 5 , this growth cone insinuated a long $(2.5 \mu \mathrm{m})$ process between an immature neuron and a radial fiber.

\section{Discussion}

The major result of this study is that callosal growth cones in the cortex follow upon a continuous fascicle of radially oriented fibers. Although the radial fibers apposed to the HRP-labeled callosal afferents were not identified immunocytochemically, several observations strongly implicate their identity as radial glial (reviewed in Voigt, 1989). First, ultrastructurally, they were characterized by a regular array of microtubules in an electronlucent cytoplasm but were most easily distinguished from other processes by their large diameter, which usually exceeded 0.8 $\mu \mathrm{m}$ (Rakic, 1971a, 1972). As in the primate cortex, large bulbous cytoplasmic protrusions devoid of microtubules were infrequently observed extending from these large-diameter fibers. Second, when postfixed with reduced osmium, they contained 25-35 nm glycogen granules (Bruckner and Diesold, 1981; Gadisseux and Fvrard, 1985). Apical dendrites of neurons are the only other cellular elements in the neuropil that are radially aligned and have a large diameter. Differentiating neurons have 
Figure 2. A, A camera lucida drawing of an HRP-labeled callosal axon with its growth cone extending into the cortex contralateral to the injection site. At this age ( $2.5 \mathrm{~d}$ postnatal), the growth cone has extended through layer 6B. The rest of the axon continues in the corpus callosum. The reference blood vessel $(B V)$ is the same in $A, B$, and $D$. The asterisk marks the same position in $A$ and $B$. The arrowhead marks the same position in $A, B$, and $D . B$, Low-magnification $(300 \times)$ photomontage of the axon shown in $A$. The HRP-labeled callosal afferent weaves in and out of the plane of the thin section from the point at which it branches toward the cortex $\left({ }^{*}\right)$ to the base of its growth cone $(>)$. Although the radial fibers to which the HRP-labeled axon is apposed cannot be seen at this magnification, the relationship of the axon (arrows) with a continuous radial fascicle can be inferred from the association of the HRP with the column of electron-dense neurons migrating on the same fascicle of radial fibers. To illustrate the direct association between the labeled callosal afferent and a fascicle of radial fibers, the region between the tailed arrows is shown enlarged in $C$. $C$, Higher-magnification $(7000 \times)$ photomicrograph of the labeled callosal afferent from the area of cortex indicated by the corresponding tailed arrows in $B$. Two fascicles of radial fibers $(R F)$ separated by processes cut in cross section illustrate the organization of the developing cortex. The labeled callosal axon (tailed arrows) is associated with the radial fascicle at right, and much of its surface is directly apposed to electron-lucent radial fibers $(R F)$. Part of the HRP-labeled axon is apposed to the trailing process of a migrating neuron $(M N)$. The neuropil between the radial fascicles contains fibers presumably traveling intracortically; the larger, vesicle-rich profiles may be growth cones. One fiber in the left radial fascicle has a microtubule-free cytoplasmic protrusion (arrowhead) characteristic of radial glial fibers. $D$, Growth cone shown in $A(11,300 \times)$. Arrows and arrowheads denote corresponding regions of the growth cone in the camera lucida drawing (inset) and the electron micrograph. The left and middle branches of the growth cone embrace a radial glial process. Two diverging radial fascicles $(R F)$ separated by $5 \mu \mathrm{m}$ are present in this micrograph. However, this stereotyped pattern of regularly spaced radial fascicles is disrupted on the right as the radial fascicle to which the growth cone is apposed is dispersed by the migrating neuron $(M N)$.

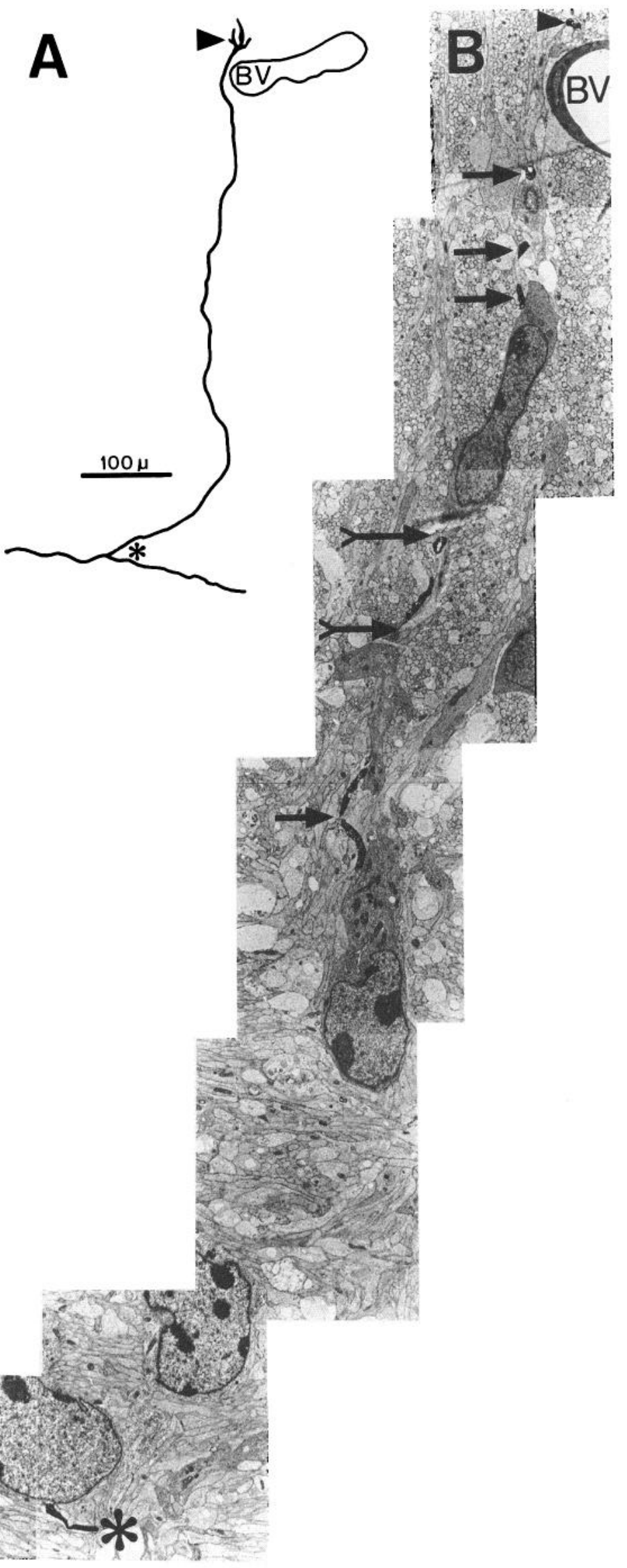



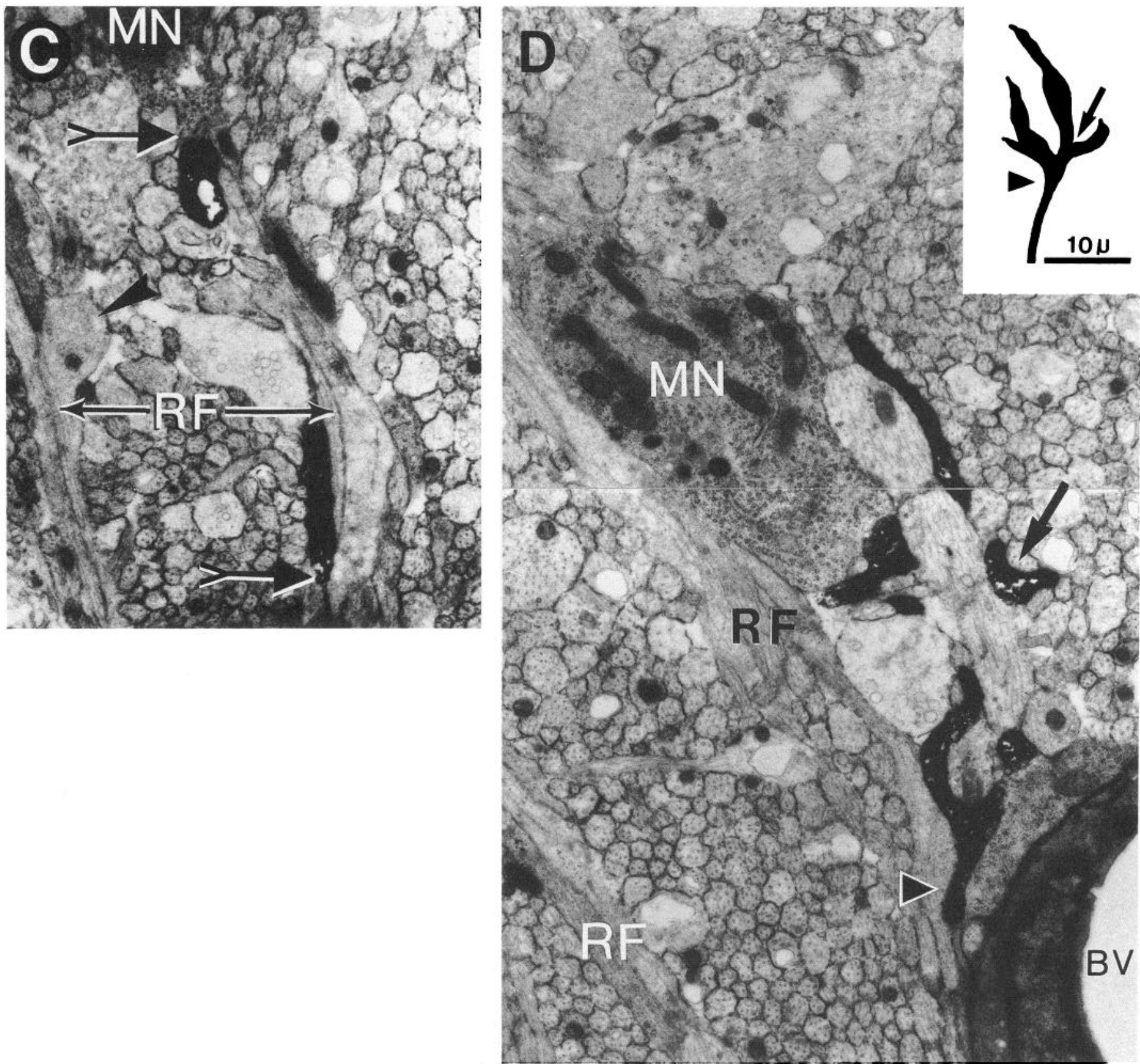

also been reported to contain glycogen granules (Borke and Nau, 1984). However, since most of the callosal afferents described in the present study are beneath differentiating layer 6 and thus beneath apical dendrites, the radially aligned fibers described in this study cannot be dendritic processes. Finally, these putative glial fibers were always associated with migrating neurons (Rakic, 1971a, 1972). Therefore, we conclude that many of the radial fibers that callosal afferents contact are indeed radial glial fibers.

The observation that callosal afferents, from the point at which they enter the cortex to their growth cones, were apposed to a continuous fascicle of radial fibers suggests that callosal afferents are tracking along radial fibers. It has been shown, however, that fascicles of radial glial fibers converge and diverge within the cortex (Misson et al., 1988; Gadisseux et al., 1989; Edwards et al., 1990; Takahashi et al., 1990). Therefore, callosal afferents associated with a continuous fascicle of radial fibers can nonetheless bend away from their radial trajectory as they follow bundles of glial processes that have diverged from their original fascicle. In this way, callosal axons tracking along radial fibers, while remaining approximately within the same radial column in the developing cortex, do not always grow in a strictly radial fashion. The trajectories of callosal afferents, visualized by light microscopic observation of 1,1'-dioctodecyl-3,3,3,3'-tetramethylindocarbocyanine perchlorate (DiI)-labeled axons, are consistent with these ultrastructural observations. While afferents generally grow perpendicular to the developing cortical layers, occasionally some fibers have a portion of their trajectory that is slightly curved (Norris and Kalil, 1989).

The present study demonstrates directly that the initial growth of callosal axons into the cortex follows radial glia. It is also likely, however, that callosal afferents continue to follow radial 


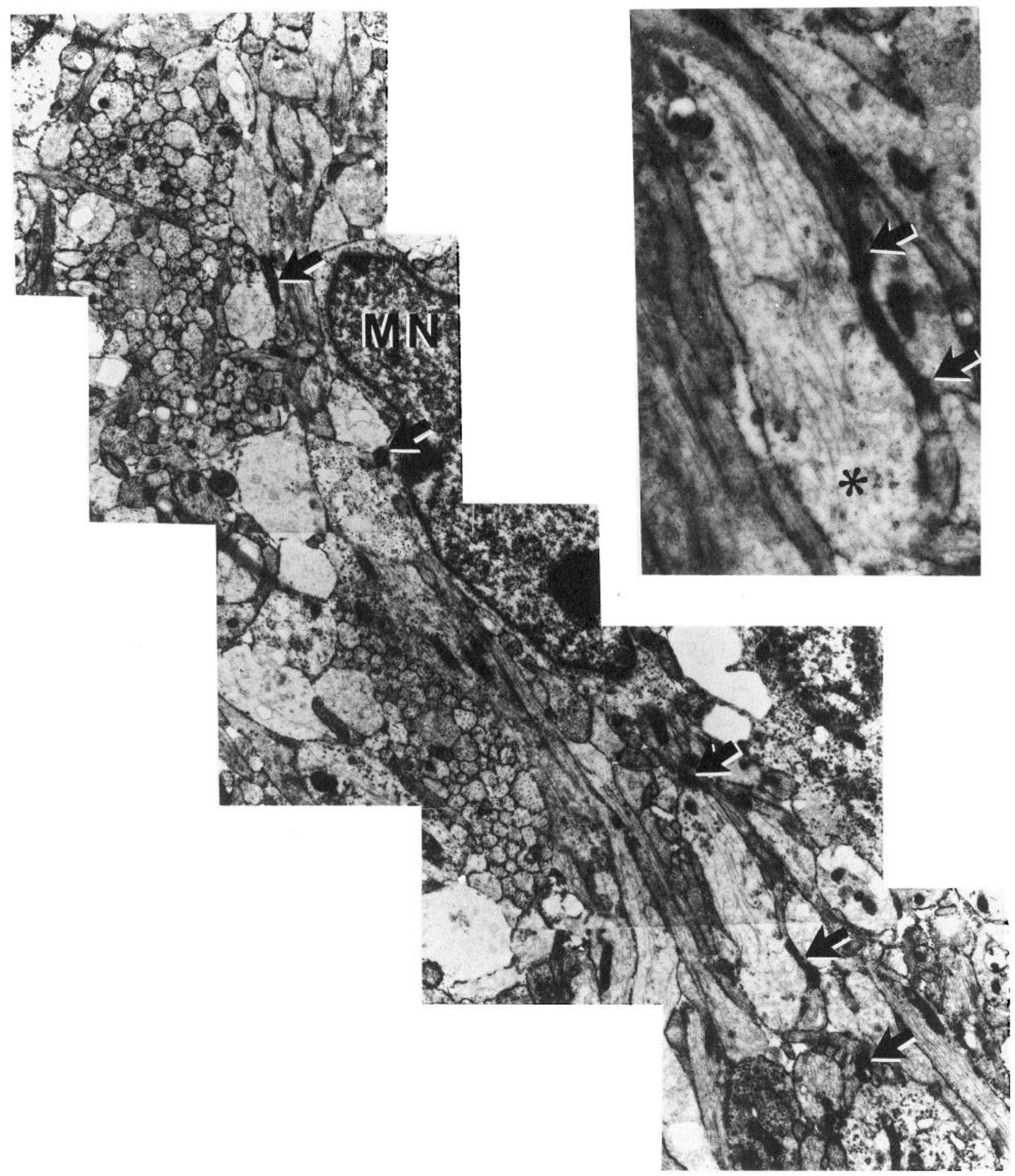

Figure 3. Photomicrographs from hamster cortex $3 \mathrm{~d}$ postnatal showing the apposition of an HRP-labeled callosal afferent to glycogen-containing radial fibers in a section fixed with reduced osmium. At left is a lower-magnification $(8800 \times)$ photomontage illustrating the relationship of an HRP-labeled callosal afferent (indicated by arrows) to a single column of radially aligned fibers and an associated migrating neuron ( $M N$ ). The chromatin in the elongated neuron is dispersing, which indicates that the neuron is beginning to differentiate. The inset at right is from an adjacent thin section $(18,000 \times)$. Glycogen granules $\left(^{*}\right)$ of $25-35 \mathrm{~nm}$, slightly larger than microtubules, are visible in the large, electron-lucent process to which the HRP-labeled afferent is apposed (arrows).

Figure 4. Photomicrographs showing an HRP-labeled callosal afferent associated with a branching fascicle of radial fibers. In $A$, the HRP-labeled callosal afferent $(6000 \times)$ appears to be associated with two adjacent radial fascicles, as indicated by the two lower arrows. However, in $B$, the higher-magnification $(9500 \times)$ photomicrograph of a thin section approximately $0.5 \mu \mathrm{m}$ away (five thin sections) shows the HRP-labeled callosal afferent extending upon the left branch of its original fascicle (lower arrow) as it converges with a "new" fascicle (top arrows). Thus, although fibers 

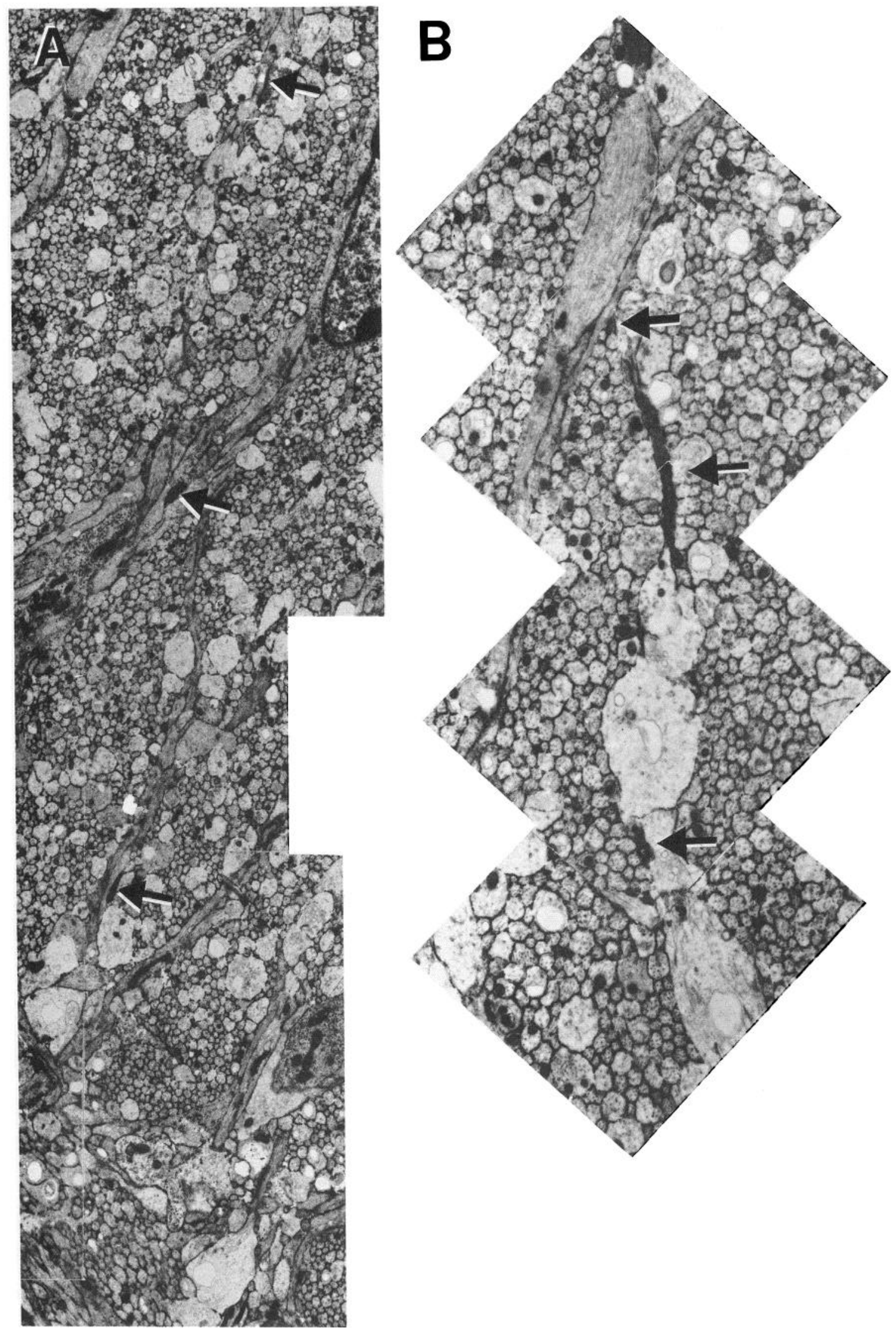

within a radial fascicle diverge, the callosal afferent remains apposed to a group of radial fibers that are part of the original radial fascicle. The three arrows do not point to corresponding regions of the axon in photomicrographs in $A$ and $B$; rather, they point to pieces of the HRP-labeled callosal afferent as it weaves in and out of the plane of section. 

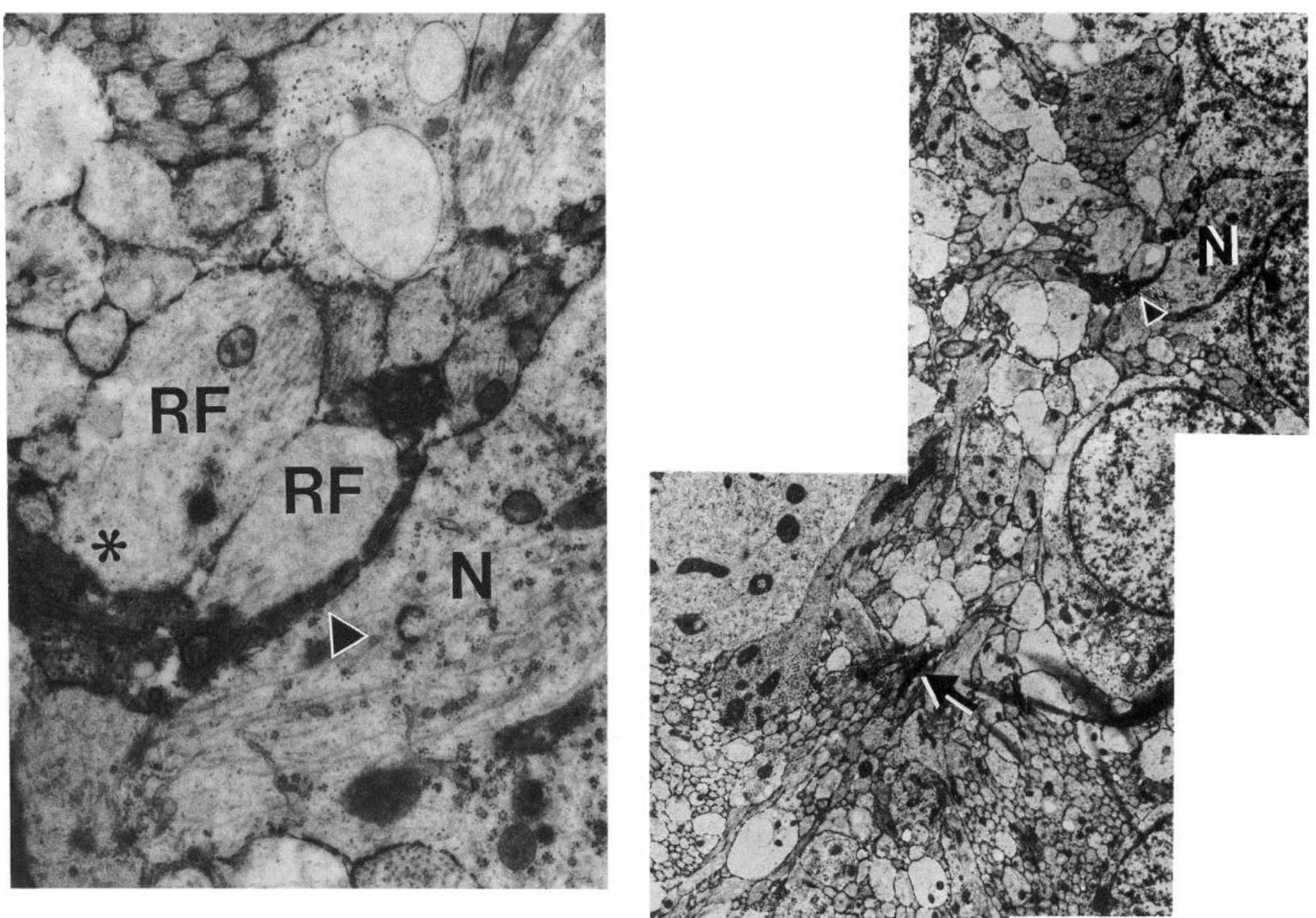

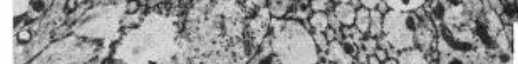

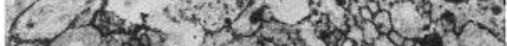
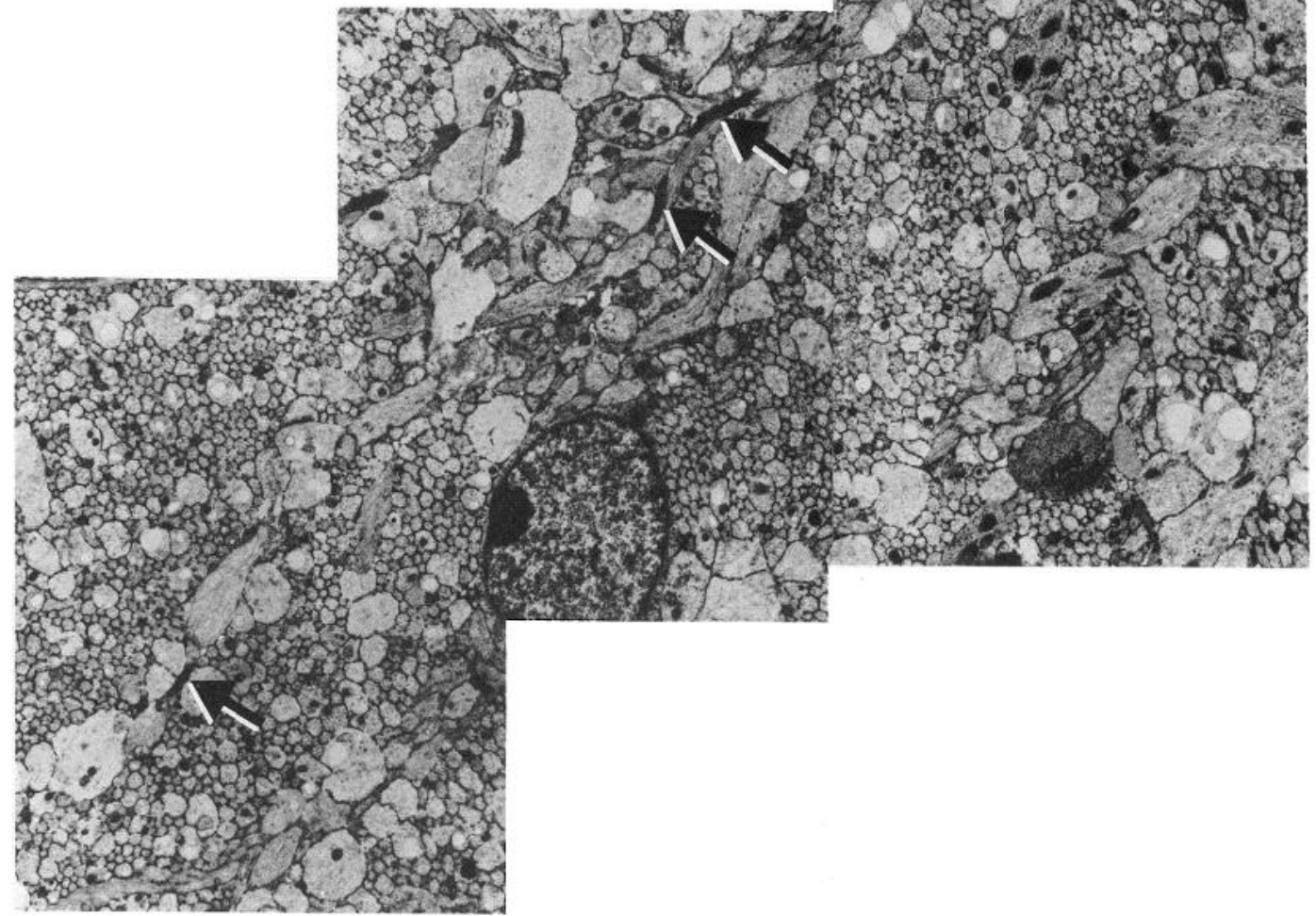

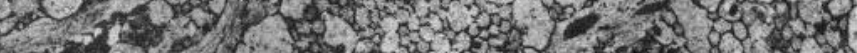

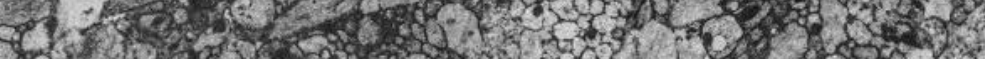

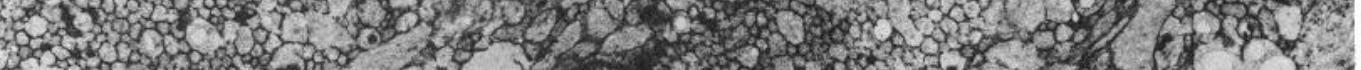

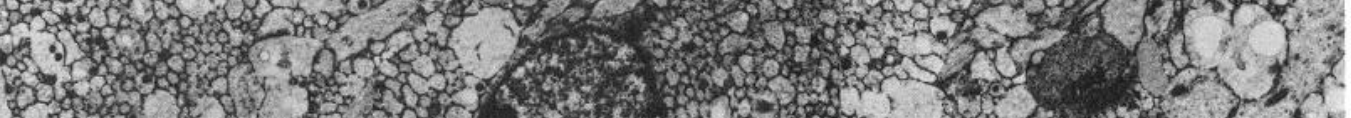

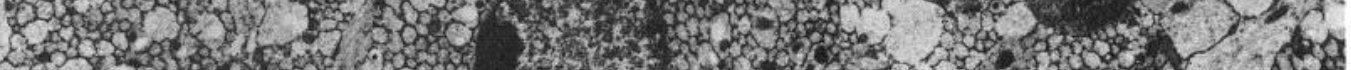
par

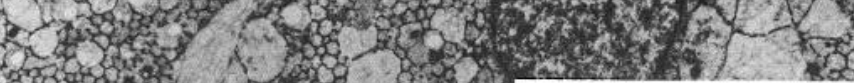
Aक Son $x$.

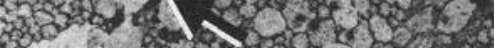
7.

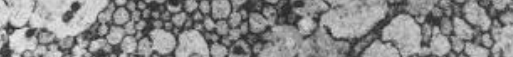

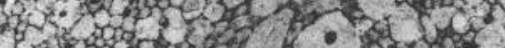
列 


\begin{tabular}{|c|c|c|c|}
\hline & \multicolumn{3}{|c|}{ Cellular element touched by afferent (\%) } \\
\hline & $\begin{array}{l}\text { Radial } \\
\text { fiber }^{a}\end{array}$ & $\begin{array}{l}\text { Migrating } \\
\text { neuron }\end{array}$ & Other ${ }^{b}$ \\
\hline \multicolumn{4}{|l|}{ Axon } \\
\hline $31-3 \mathrm{~J} 3$ & 62 & 18 & 20 \\
\hline 34-4A3 & 57 & 13 & 30 \\
\hline 34-4A2 & 51 & 22 & 27 \\
\hline $33-9 A 2$ & 64 & 7 & 29 \\
\hline $34-6 \mathrm{~B} 4$ & 48 & 10 & 32 \\
\hline \multicolumn{4}{|c|}{ Growth cone } \\
\hline $31-3 \mathrm{~J} 3$ & 63 & - & 37 \\
\hline $34-4 \mathrm{A3}$ & 36 & 14 & 50 \\
\hline $34-4 \mathrm{~A} 2$ & 59 & - & 41 \\
\hline $33-9 A 2$ & 40 & - & 60 \\
\hline $34-6 \mathrm{~B} 4$ & 56 & 22 & 22 \\
\hline
\end{tabular}

The percentage of the total surface area of five HRP-labeled callosal afferent axons and their growth cones in contact with either radial fibers, migrating neurons, or other processes. For each afferent, photomicrographs of the portion of every thin section containing HRP label were printed at 25,000×. Each section was drawn as in Figure 6 to classify the cellular elements in contact with the entire axon and growth cone. The perimeter of each HKP-labeled profile was traced using JAva video analysis software (Jandel Scientific), which can measure irregular lengths with high ( $\pm 2 \%$ ) accuracy. The length of the segment of the perimeter touching radial fibers, migrating neurons, or other cellular processes was noted, summed from every thin section for each category, and divided by the total perimeter length to obtain the percentages in the table.

a "Radial fibers" include only the radially oriented profiles that were electron lucent with a regular array of microtubules and a diameter greater than $0.7 \mu \mathrm{m}$.

$b$ "Other" includes processes such as axons, dendrites, and cellular processes within the radial fascicles that did not meet the criteria to be identified as "radial."

glia as they ascend to more superficial cortical layers. Examination of labeled callosal afferents in the present study could not be extended beyond the $3 \mathrm{~d}$ postnatal time point, because after this age HRP failed to fill callosal axons as far as their growth cones. Nevertheless, in a subsequent study of older animals, we used the fluorescent tracer DiI to label growing callosal axons and observed that callosal axons continue to grow radially through the developing cortex until $8 \mathrm{~d}$ postnatal (Norris and Kalil, 1989). Moreover, because radial glia span the cerebral wall, they are able to guide the growth of axons up to the pial surface.

A schematized three-dimensional reconstruction of the HRPlabeled axon of Figures 2 and 6 is drawn in Figure 7 to illustrate clearly our proposed scheme of the relationship between callosal afferents and fascicles of radial fibers. Our model is adapted from that of Rakic $(1972,1988)$ to emphasize that the growth of callosal axons along radial glia is concomitant with ncuronal migration along radial glia. Because we never observed callosal afferents that were not clearly apposed to radial fascicles along a significant extent of their axons and growth cones, we propose that radial glia comprise a significant substrate for growing callosal axons. Given the appearance of radial glia well before the growth of afferent axons and the consistent tracking of callosal axons along these glia, it is reasonable to suppose that radial glia play a role in the guidance of callosal afferents through the developing cortex.

The present study does not define the precise role that glia play in guiding callosal axons. One possibility is that radial glia act as a preformed mechanical substratum, providing a path of least resistance from the callosum to superficial layers of neocortex through the dense maze of horizontal fibers. Wilhelm His was the first to recognize the importance of mechanical factors in neuroembryology, having observed that axons entering the spinal cord follow the longitudinal structures (spongioblasts) of the dorsal columns until they reach the surface of the spinal cord (reviewed in Picken, 1956). A more detailed theory of mechanical guidance, termed contact guidance, was supported by subsequent experiments in vitro showing that neurite outgrowth follows the direction of tension in plasma clots (Weiss, 1941). Similarly, neural-glial adhesion molecules could mediate contact guidance by radial glia and provide a generic pathway, much as radial glia appear to provide a general guidance substrate for the migration of neurons in the CNS (reviewed in Hatten, 1990). If this model were correct, callosal axons would grow equally well on radial glia from homotopic (target) and heterotopic (nontarget) regions of cortex. Alternatively, radial

Figure 5. At right, low-magnification (6900 $\times$ ) photomicrograph of an HRP-labeled callosal afferent (arrows) whose growth cone (arrowhead and inset at left) has penetrated farther into the cortex than the other callosal afferents in this study. The growth cone has reached a layer of immature neurons that, although not completely differentiated, have ceased migration. In more superficial regions of the cortex, the organization of the cortex into bundles of radial fibers separated by smaller processes coursing horizontally becomes less pronounced; the upper third of the photomontage shows the fascicle of radial fibers weaving between immature neurons. The HRP-labeled callosal afferent remains associated with a continuous bundle of radial fibers to the base of its growth cone (arrowhead). At upper left is the growth cone shown at higher magnification $(24,000 \times)$, which (seen in the light microscope) had a narrow, tapered morphology. The tip insinuates between the trailing process of an immature neuron ( $N$ ) and a radial process $(R F)$. The asterisk marks the location of preserved glycogen granules. 


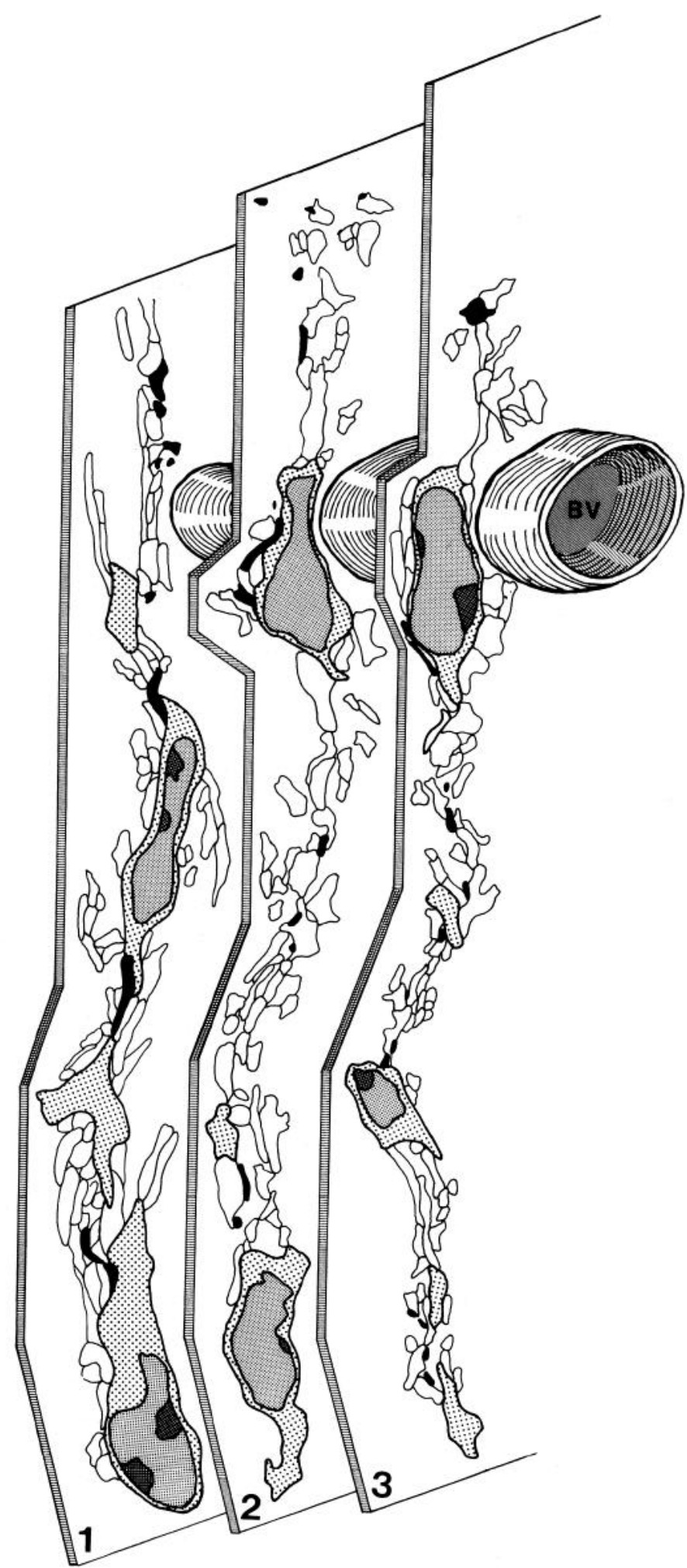

Figure 6. Composite drawings of three aligned thin sections of the HRP-labeled callosal afferent shown in Figure 2. The drawing emphasizes the relationship of the single callosal axon to radial fibers and migrating neurons. 1 is a tracing of a photomontage from the thin section adjacent to that shown in Figure 2; 2 and 3 are traced from thin sections approximately 1.2 and $2.0 \mu \mathrm{m}$ away (15 and 25 sections) from 1 , respectively. Solid profiles are the HRP-filled axon or growth cone. Radial fibers are drawn as open profiles. Migrating neurons with leading and trailing processes are stippled; nuclei and nucleoli have denser stipple. Axons, dendrites, and processes that could not be unambiguously identified were not traced. $B V$, blood vessel.

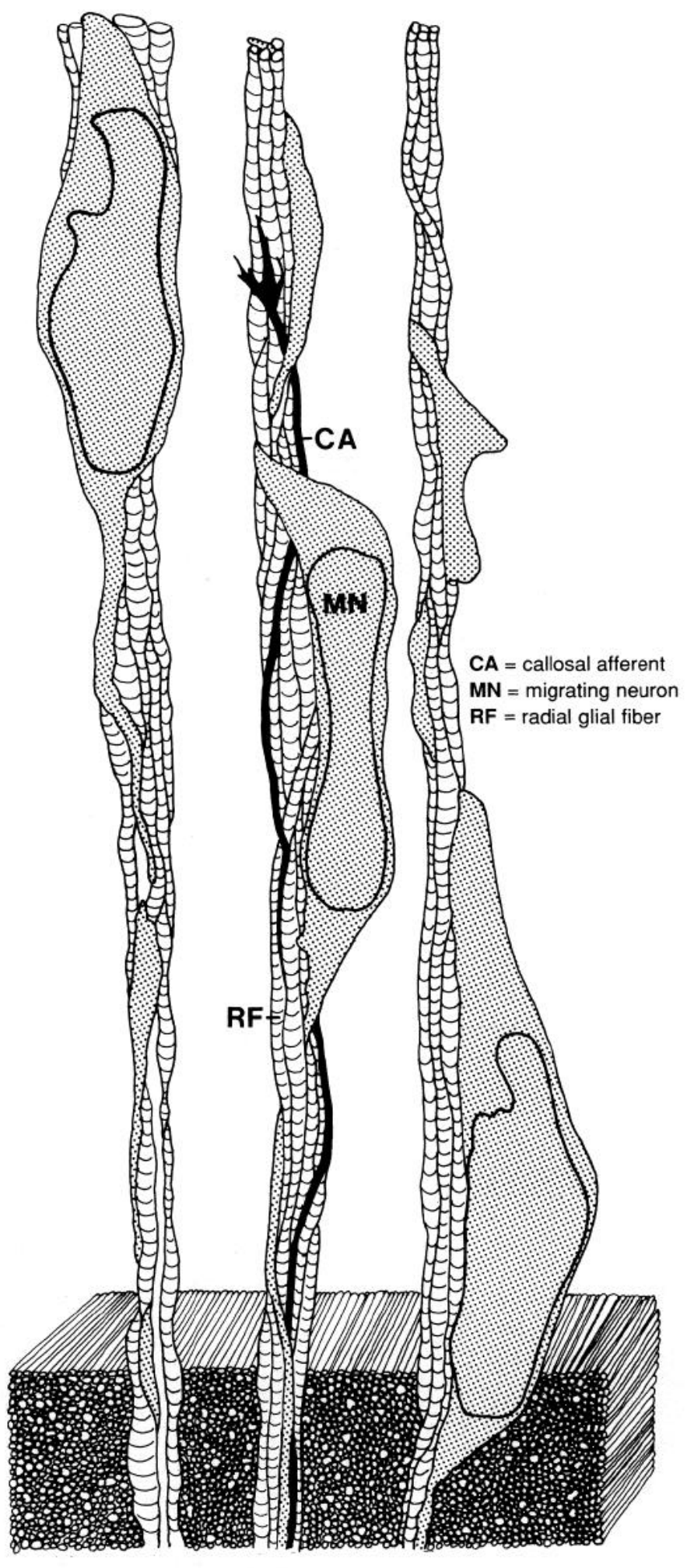

Figure 7. A schematic reconstruction illustrating the proposed relationship between callosal afferents $(C A)$ and radial glial fascicles $(R F)$ and their associated migrating neurons $(M N)$ based on serial drawings like those in Figure 6 . The neuropil between radial fascicles was simplified and shows only axons in cross section. The model emphasizes the extension of a callosal afferent along a continuous fascicle of radial glial fibers at a time when neurons are migrating. Adapted from Rakic (1972, 1988). 
glia may provide a more specific pathway for afferent outgrowth. In an earlier study, we showed that the topographic pattern of the initial growth of callosal afferents into cortex is homotopic as in the adult, suggesting that initial growth into the cortex is directed to topographically appropriate regions (C. Norris and $\mathrm{K}$. Kalil, unpublished observations). In order for radial glia to provide a specific guidance pathway for callosal afferents, spatially discrete subsets of glia would need to be recognized by topographically appropriate callosal axons.

An important role for radial glia in the guidance of callosal axons through the cortex does not exclude other guidance mechanisms. Multiple cellular elements and molecular factors may play a role in the guidance of callosal axons through the cortex. Afferent and possibly efferent callosal axons grouped within the radial fiber bundles may be important, especially for the guidance of later-arriving callosal afferents. In addition, in more supcrficial laycrs of cortex, growth cones will encounter radially oriented apical dendrites that could help guide callosal afferents.

\section{Implications for the development of cortical organization}

The guidance of afferent axons by radial glia could provide a mechanism for connecting callosal axons with developing cortical columns in the cerebral cortex. A striking characteristic of the adult neocortex is its columnar organization (Mountcastle, 1957; Hubel and Wiesel, 1962). Rakic (1988) proposed the radial unit model to describe how functional columns might be established during cortical development. Briefly, during neurogenesis, neighboring cells in the ventricular zone, by migrating along common radial glial guides, remain within the same radial column. In this way, ontogenetic columns are formed that will give rise to functional columns in the mature cortex. The present results are consistent with a hypothesis that callosal afferents, by extcnding upon a continuous fascicle of radial glia, establish an early relationship with ontogenetic columns. In this way, callosal axons could first establish their columnar territory before extending lateral branches.

An early relationship between callosal afferents and ontogenetic columns could be significant for the differentiation of physiological responses of cortical cells. In the somatic sensory cortex, columns running perpendicular to the surface of the cortex are approximately cylindrical in shape with a diameter, in rodents, of 250-400 $\mu \mathrm{m}$ (Welker, 1971). Cells within a column show similar submodality and receptive field properties in response to peripheral stimuli (Mountcastle, 1957; Hubel and Wiesel, 1962). Altering the thalamic input to primary sensory cortex alters the response properties and the organization of the recipient cortex (reviewed in Sur et al., 1990), suggesting that thalamic input dictates the response properties of cortical cells. Although less wcll charactcrized, callosal projections from the sensorimotor cortex are arranged in columnlike arrays that are often similar in size to the physiologically defined columns (Wise and Jones, 1976; Jones et al., 1979; Isseroff et al., 1984). Callosal afferents, by extending along radial glia at a time when neurons are still migrating, could direct the columnar parcellation of their target cortex at an early developmental stage. Other afferent systems may be guided by radial glia as well and would therefore also form an early relationship with ontogenetic columns.

\section{References}

Adams JC (1981) Heavy metal intensification of DAB-based HRP reaction product. J Histochem Cytochem 29:775.

Akers RM, Killackey HP (1978) Organization of the corticocortical connections in the parietal cortex of the rat. J Comp Neurol 181:513538.

Bitner C, Benjelloun-Touimi S, Dupouey P (1987) Palisading pattern of subpial astroglial processes in the adult rodent brain: relationship between the glial palisading pattern and the axonal and astroglial organization. Brain Res 465:167-168.

Borke RC, Nau ME (1984) Glycogen, its transient occurrence in neurons of the rat CNS during normal postnatal development. Dev Brain Res 16:277-284.

Bruckner G, Diesold D (1981) Histochemistry of glycogen deposition in the perinatal rat brain: importance of radial glial cells. J Neurocytol 10:749-757.

Carvell GE, Simons DJ (1987) Thalamic and corticocortical connections of the second somatic sensory area of the mouse. J Comp Neurol 265:409-427.

Choi BH, Lapham LW (1978) Radial glia in the human fetal cerebrum: a combined Golgi, immunofluorescent and electron microscopic study. Brain Res 148:295-311.

Culican SM, Baumrind NL, Yamamoto M, Pearlman AL (1990) Cortical radial glia: identification in tissue culture and evidence for their transformation to astrocytes. J Neurosci 10:684-692.

Dupouey P, Benjelloun S, Gomes D (1985) Immunohistochemical demonstration of an organized cytoarchitecture of the radial glia in the CNS of embryonic mouse. Dev Neurosci 7:81-93.

Edwards MA, Yamamoto M, Caviness VS Jr (1990) Organization of radial glial and related cells in the developing murine CNS. An analysis based upon a new monoclonal antibody marker. Neuroscience 36:121-144.

Engel AK, Muller CM (1989) Postnatal development of vimentinimmunoreactive radial glial cells in the primary visual cortex of the cat. J Neurocytol 18:437-450.

Fallon JF (1985) Preferential outgrowth of central nervous system neurites on astrocytes and Schwann cells as compared with nonglial cells in vitro. J Cell Biol 100:198-207.

Gadisseux J-F, Evrard P (1985) Glial-neuronal relationship in the developing central nervous system. Dev Neurosci 7:12-32.

Gadisseux J-F, Evrard P, Misson JP, Caviness VS Jr (1989) Dynamic structure of the radial glial fiber system of the developing murine cerebral wall: a quantitative immunocytochemical analysis. Dev Brain Res 50:55-68.

Guillery RW, Walsh C (1987) Changing glial organization relates to changing fiber order in the developing optic nerve of ferrets. J Comp Neurol 265:203-217.

Hatten MB (1990) Riding the glial monorail: a common mechanism for glial-guided neuronal migration in different regions of the developing mammalian brain. Trends Neurosci 13:179-184.

Hirano M, Goldman JE (1988) Gliogenesis in rat spinal cord: evidence for origin of astrocytes and oligodendrocytes from radial precursors. J Neurosci Res 21:155-167.

Hubel KH, Wiesel TN (1962) Receptive fields, binocular interaction and functional architecture in the cat's visual cortex. J Physiol (Lond) 260:106-154.

Isseroff A, Schwartz ML, Dekker JJ, Goldman-Rakic PS (1984) Columnar organization of callosal and associational projections from rat frontal cortex. Brain Res 293:213-223.

Jacobs JR, Goodman CS (1989) Embryonic development of axon pathways in the Drosophila CNS. II. Behavior of pioneer growth cones. J Neurosci 9:2412-2422.

Jones EG, Burton H, Porter R (1975) Commissural and corticocortical "columns" in the somatic sensory cortex of primates. Science 190: 670-674.

Jones EG, Coulter JD, Wise SP (1979) Commissural columns in the sensory-motor cortex of monkeys. J Comp Neurol 188:113-136.

Killackey HP, Gould HJ III, Cusick CG, Pons TP, Kaas JH (1983) The relation of the corpus callosal connections to architectonic fields and body surface maps in new and old world monkeys. J Comp Neurol 219:384-419.

Koralek KA, Olavarria J, Killackey HP (1990) Areal and laminar organization of corticocortical projections in the rat somatosensory cortex. J Comp Neurol 299:133-150.

LcVinc SM, Goldman JE (1988) Embryonic divergence of oligodendrocyte and astrocyte lineages in developing rat cerebrum. J Neurosci 8:3992-4006.

Levitt P, Rakic P (1980) Immunoperoxidase localization of glial fibrillary acid protein in radial glial cells and astrocytes of the developing rhesus monkey brain. J Comp Neurol 193:815-840. 
Miller MW, Vogt BV (1984) Heterotopic and homotopic callosal connections in rat visual cortex. Brain Res 297:75-89.

Misson JP, Edwards MA, Yamamoto M, Caviness VS Jr (1988) Identification of radial glial cells within the developing murine central nervous system: studies based upon a new immunohistochemical marker. Dev Brain Res 44:95-108.

Mountcastle VB (1957) Modality and topographic properties of single neurons of cat's somatic sensory cortex. J Physiol (Lond) 20:408434.

Noble M, Fok-Seang J, Cohen J (1984) Glia are a unique substrate for the in vitro growth of central nervous system neurons. J Neurosci 4:1892-1903.

Norris CR, Kalil K (1989) Development of callosal arbors in the hamster sensorimotor cortex. Soc Neurosci Abstr 15:874.

Norris CR, Kalil K (1990) Morphology and cellular interactions of growth cones in the developing corpus callosum. J Comp Neurol 293: 268-281.

Olavarria J, Van Sluyters RC, Killackey HP (1984) Evidence for the complementary organization of callosal and thalamic connections within rat somatosensory cortex. Brain Res 291:364-368.

Picken L (1956) The fate of Wilhelm His. Nature 178:1162-1165.

Rakic P (1971a) Neuron-glia relationship during granule cell migration in developing cerebellar cortex. A Golgi and electron microscopic study in Macacus rhesus. J Comp Neurol 141:283-312.

Rakic P (1971b) Guidance of neurons migrating to the fetal monkey neocortex. Brain Res 33:471-476.

Rakic P (1972) Mode of cell migration to the superficial layers of fetal monkey neocortex. J Comp Neurol 145:61-89.

Rakic P (1988) Specification of cerebral cortical areas. Science 241: 170-176.

Schmechel DE, Rakic P (1979) A Golgi study of radial glial cells in developing monkey telencephalon: morphogenesis and transformation into astrocytes. Anat Embryol 156:115-152.

Shimada M, Langman J (1970) Cell proliferation, migration and differentiation in the cerebral cortex of the golden hamster. J Comp Neurol 139:227-244.
Silver J, Lorenz SE, Wahlstein D, Coughlin J (1982) Axonal guidance during development of the great cerebral commissures: descriptive and experimental studies in vivo on the role of preformed glial pathways. J Comp Neurol 210:10-29.

Smith GM, Miller RH, Silver J (1986) Changing role of forebrain astrocytes during development, regenerative failure, and induced regeneration upon transplantation. J Comp Neurol 251:23-43.

Sretevan DW, Shatz CJ (1987) Axon trajectories and pattern of terminal arborization during the prenatal development of the cat's retinogeniculate pathway. J Comp Neurol 255:386-400.

Sur M, Pallas SH, Roe AW (1990) Cross-modal plasticity in cortical development: differentiation and specification of sensory neocortex. Trends Neurosci 13:227-233.

Takahashi T, Misson JP, Caviness VS Jr (1990) Glial process elongation and branching in the developing murine neocortex: a qualitative and quantitative immunohistochemical analysis. J Comp Neurol 302:15-28.

Voigt T (1989) Development of glial cells in the cerebral wall of ferrets: direct tracing of their transformation from radial glia into astrocytes. J Comp Neurol 289:74-88.

Weiss $P$ (1941) Nerve patterns: the mechanics of nerve growth. Growth, Third Growth Symp 5:163-203.

Welker C (1971) Microelectrode delineation of fine grain somatotopic organization of SmI cerebral neocortex in albino rat. Brain Res 26: 259-275.

Wilson MA, Taylor JSH, Gazc RM (1988) A developmental and ultrastructural study of the optic chiasma in Xenopus. Development 102:537-553.

Wise SP, Jones EG (1976) The organization and postnatal development of the commissural projection of the rat somatic sensory cortex. J Comp Neurol 168:313-344.

Yorke CH, Caviness VS Jr (1975) Interhemispheric neocortical connections of the corpus callosum in the neonatal mouse: a study based on anterograde and retrograde methods. J Comp Neurol 164:233246. 